\title{
Self-assessment of individual differences in language switching
}

\section{Antoni Rodriguez-Fornells ${ }^{1,2,3} *$, Ulrike M. Krämer ${ }^{4,5}$, Urbano Lorenzo-Seva ${ }^{6}$, Julia Festman ${ }^{7}$ and Thomas F. Münte ${ }^{5}$}

${ }^{1}$ Cognition and Brain Plasticity Group, Bellvitge Biomedical Research Institute, L'Hospitalet de Llobregat, Barcelona, Spain

${ }^{2}$ Department of Basic Psychology, L'Hospitalet de Llobregat, University of Barcelona, Barcelona, Spain

${ }^{3}$ Catalan Institution for Research and Advanced Studies, Barcelona, Spain

${ }^{4}$ Helen Wills Neuroscience Institute, University of California at Berkeley, Berkeley, CA, USA

${ }^{5}$ Department of Neurology, University of Lübeck, Lübeck, Germany

${ }^{6}$ Deparment of Psychology, Universitat Rovira i Virgili, Tarragona, Spain

7 Institute of Psychology, University of Magdeburg, Magdeburg, Germany

\section{Edited by:}

Teresa Bajo, Universidad de Granada, Spain

\section{Reviewed by:}

Tamar H. Gollan, University of

California, USA

Mirjam Broersma, Max Planck

Institute for Psycholinguistics,

Netherlands

\section{*Correspondence.}

Antoni Rodriguez-Fornells,

Department of Basic Psychology,

L'Hospitalet de Llobregat, University

of Barcelona, Campus Bellvitge,

Barcelona 08097, Spain.

e-mail: antoni.rodriguez@icrea.es
Language switching is omnipresent in bilingual individuals. In fact, the ability to switch languages (code switching) is a very fast, efficient, and flexible process that seems to be a fundamental aspect of bilingual language processing. In this study, we aimed to characterize psychometrically self-perceived individual differences in language switching and to create a reliable measure of this behavioral pattern by introducing a bilingual switching questionnaire. As a working hypothesis based on the previous literature about code switching, we decomposed language switching into four constructs: (i) L1 switching tendencies (the tendency to switch to L1; L1-switch); (ii) L2 switching tendencies (L2-switch); (iii) contextual switch, which indexes the frequency of switches usually triggered by a particular situation, topic, or environment; and (iv) unintended switch, which measures the lack of intention and awareness of the language switches. A total of 582 Spanish-Catalan bilingual university students were studied. Twelve items were selected (three for each construct). The correlation matrix was factor-analyzed using minimum rank factor analysis followed by oblique direct oblimin rotation. The overall proportion of common variance explained by the four extracted factors was 0.86 . Finally, to assess the external validity of the individual differences scored with the new questionnaire, we evaluated the correlations between these measures and several psychometric (language proficiency) and behavioral measures related to cognitive and attentional control. The present study highlights the importance of evaluating individual differences in language switching using self-assessment instruments when studying the interface between cognitive control and bilingualism.

Keywords: bilingualism, natural language switching, cognitive control, psychometric

\section{INTRODUCTION}

Language switching is an omnipresent behavior that characterizes bilingual individuals and communities. This process occurs when bilinguals alternate between two languages while talking to others. In fact, the ability to switch languages or code switch ${ }^{1}$ is a very fast, efficient, and flexible process seen in a wide range of bilingual language processing situations. Code switching consists of alternating between or mixing two languages within a single discourse or episode, sentence or constituent, often with no change of interlocutor or topic. Although some authors and

\footnotetext{
${ }^{1}$ In the present manuscript, we did not make any distinction between language mixing/switching and code switching. It is important to mention that the distinction between code switching and language switching, code mixing and borrowings, among others, is controversial. At times, code switching refers to the use of various linguistic units across sentence boundaries, whereas code mixing refers to mixing linguistic units within a sentence (Hatch, 1976; McLaughlin, 1984). However, following other authors (see extended discussion in Bhatia and Ritchie, 1996), we preferred to use these terms indiscriminately to reflect the language switches observed in bilinguals.
}

theoretical approaches (from foreign language teaching) have previously deemed code switching to be problematic and an index of poor linguistic competence, the current prevailing view is that code switching is a natural and positive aspect of the bilingual individual's linguistic experience and discourse (Zentella, 1997). For example, Poplack (1980), who collected data on natural conversations in Spanish-English Puerto Rican bilinguals in New York, concluded that code switching is a language skill that reflects a high degree of competence and proficiency in bilinguals and that it is more frequent when both languages were learned in early childhood (Miccio et al., 2009). Moreover, code switching may also occur voluntarily and represent a communication strategy for bilinguals to achieve a specific communication goal.

Although a plethora of studies have been devoted to code switching, an important aspect that has been neglected in psycholinguistic, linguistic, and sociolinguistic approaches to this phenomenon is the role of individual differences in language switching (however, see Weinreich, 1953). From a psycholinguistic point of view, it is important to understand what causes natural 
language switches, how an utterance is prepared and produced during a natural code switch, how bilinguals understand and comprehend a mixed language input, how bilinguals are aware of the appropriate language to use and how they control code switching tendencies. Code switching tendencies may depend on many elements, including cognitive factors (proficiency in the languages in use, cognitive control functions, cognitive flexibility, general level of cognitive abilities, and personality traits) and other sociopsychological factors (Grosjean, 1982). From a social perspective, any language switch is embedded in a specific social context. Therefore, some authors have proposed that the following factors contribute to language switches: (i) social roles (socioeconomic status, educational background, and relationships between the participants), (ii) situational factors (discourse topic and language suitability in specific contexts), (iii) message-intrinsic considerations (e.g., repetitions, clarifications, emphasis, quotations, and message qualification), and (iv) language attitudes (social dominance, group membership, and security; Ritchie and Bhatia, 2006). In the following paragraphs, we will briefly review the main factors affecting language switching as they relate to linguistic needs (competence, proficiency, and language borrowings) and pragmatic - contextual aspects. Further, we discuss the possible role of interindividual differences in language switching.

\section{LINGUISTIC AND PSYCHOLINGUISTIC FACTORS AFFECTING LANGUAGE SWITCHING}

Language switching might be caused by linguistic factors such as proficiency, word semantics, or language similarity (Grosjean, 1982; Poulisse and Bongaerts, 1994; Genesee et al., 2004). Regarding proficiency, language switching frequently occurs due to a lack of knowledge of words in the language being used (L2; Grosjean, 1982). This pattern of switching has been also observed in bilingual children when their linguistic competencies in their less frequently used language are not fully developed and they need to fill their lexical gaps with a word from the other language (Genesee et al., 2004). In addition, in some situations, bilinguals may be faster in accessing the word in their dominant language and tend to produce this utterance instead of the one in the target language. These switching patterns could also be favored in mixed language environments in which both languages are kept highly activated and are further reinforced by the interference that bilinguals experience in language production (Poulisse and Bongaerts, 1994; Colomé, 2001; Rodriguez-Fornells et al., 2005).

Indeed, Gollan and Ferreira (2009) recently reported that balanced Spanish-English bilinguals tend to switch languages more often than unbalanced bilinguals when language switching was measured by the number of times that participants voluntarily switched languages in a naming task. The authors of this study concluded that language switching could be considered to be beneficial in some circumstances and that these switches might be driven by the lexical accessibility of specific words in each language (Poplack, 1980; Clyne, 2003; Owens, 2005). Although it occurs less frequently, the inverse situation (i.e., faster recruitment of L2 than L1 words) may also occur. In some cases, this phenomenon can be observed in the early stages of learning a new language, likely because of the intensive and repetitive practice of novel words.
In addition, the lack of use of the $\mathrm{L} 1$ due to the immersion in exclusively L2 environments may result in L1 being deactivated (see Grosjean, 1998), resulting in the faster access to L2 words (see for example, Linck et al., 2009).

Semantic factors also have to be taken into account in language switching. For example, there may be words in one language that describe a concept in a very specific way and have no semantically equivalent words in the other language (Bowerman and Choi, 2001; Ameel et al., 2005; Francis, 2005). In particular, abstract or ambiguous types of concepts might not be mapped directly onto corresponding words (Van Hell and De Groot, 1998; Kroll and Tokowicz, 2001; Dong et al., 2005). In this sense, interference from the other language could be considered an accidental code switch, but in due time, it could lead to conscious lexical borrowing (loanword) from the other language (e.g., the words "fax," "spam," and "mouse" in Spanish or "patio" in English).

In addition, the similarity of the two languages spoken in a community could be reflected in the degree of switching (Odlin, 1989; Marian, 2009). For example, Catalan-Spanish languages are highly similar Romance languages, sharing a large number of cognate words with similar forms and meanings ["vender" (Spanish) - "vendre" (Catalan), to sell], and switching is commonly observed in many situations (Rodriguez-Fornells et al., 2006; see also Calsamiglia and Tuson, 1984; Woolard, 1988). Interestingly, early observations of naturalistic conversations have suggested that cognate words could act as a language switching trigger. For example, Clyne (1967) observed that code switches frequently occurred close to the use of a cognate word, and he also noticed that "trigger words" existed in the speech of German-English bilinguals that provoked a more or less unconscious switch from one language to the other (see Clyne, 1972). Broersma and De Bot (2006) extended these observations to show that words spoken directly after a cognate word or in the same basic clause were significantly more often code-switched than other words. These results regarding the cognate-related triggering of code switching fit quite well with the idea that both languages are interfering at the production level in bilinguals (Rodriguez-Fornells et al., 2005). If that is the case, the activation of a cognate word in the non-target language may spread activation to associated non-target lexical candidates, and therefore, it would increase the chance of observing a language change. Broersma and De Bot (2006) also found that producing a cognate word is a much more powerful trigger of language switching than hearing a cognate word (Broersma et al., 2009).

\section{SOCIOPRAGMATIC FACTORS AFFECTING LANGUAGE SWITCHING}

From a pragmatic point of view, bilinguals choose their language of interaction instantaneously and smoothly, in most of the cases even unconsciously, as a function of whom they are talking to (participants, backgrounds, relationships), what they are talking about (topic, content) and when and where the interaction is taking place. Even small children show language switching abilities and adapt their language to the context and the interlocutor (Petitto et al., 2001). For example, Comeau et al. (2003) showed that six French-English bilingual children (2-4 years old) adjusted their rates of language mixing to the rates of code switching used by the experimenter. Thus, accommodating the language use of the 
interlocutor appears to be important in bilingual language switching (Petitto et al., 2001; Genesee et al., 2004). If both speakers are able to understand both languages in everyday conversation, code switching might seem natural and acceptable. Code switching is often observed in bilingual families, in particular between siblings being raised abroad from their parent countries. Zentella (1997) observed that bilinguals tend to code switch more in familiar informal settings, implying that extralinguistic social factors such as group identity, age, or gender might modulate language mixing tendencies (Milroy and Gordon, 2003). This code switching pattern observed with friends and family members is very interesting and suggests that it may be easier or more economical in general to mix languages than to keep languages separate. This phenomenon could even imply that some extra effort must be expended to maintain single language production in this type of familiar, informal setting.

Corroborating the role of extralinguistic factors, a particular language is often viewed as more suitable for certain groups, settings, and topics in bilingual societies (Ritchie and Bhatia, 2006). Indeed, many bilinguals use different languages for their public and private "worlds." To this point, Timm (1975) reported that Mexican-American Spanish-English bilingual speakers switched to Spanish to convey personal feelings or to converse about aspects of their culture but switched to English to convey more objective information. The advantage, at the semantic level, of having different ways to express the same ideas permits balanced bilinguals to creatively switch between languages, allowing for special effects in their communication that are not available to monolingual speakers (Zentella, 1997; Auer, 1998). Importantly, such creative use of switching is seen as positive in some societies, favoring conscious, and unconscious switching (e.g., Puerto Rican English-Spanish bilinguals in New York City, EnglishHindi mixing in India, and Arabic-French-English mixing in Lebanon; Grosjean, 1982; Poplack, 1985). In contrast, other societies show negative attitudes toward language switching, often due to cultural-historical and linguistic conflicts (e.g., FlemishFrench bilinguals in Brussels; Spanish-Catalan bilinguals during the Franco era, Woolard, 1988). Thus, sociolinguistic factors seem to be a prime source of variation in language mixing tendencies in real life and likely will influence and interact with the inherent dynamics of the cognitive systems that support this ability.

\section{INDIVIDUAL DIFFERENCES IN LANGUAGE SWITCHING AND COGNITIVE CONTROL}

An additional important factor in language switching is individual differences. Marked interindividual variability has been reported in children raised in bilingual regions (e.g., ranging from 2 to $10 \%$ mixing within a single utterance in French-English children from Montreal; see Genesee et al., 2004). At times, speakers show a lack of awareness of the language switch (lack of "metalinguistic awareness"). ${ }^{2}$ Weinreich (1953) distinguished those who have

\footnotetext{
${ }^{2}$ Metalinguistic awareness is defined in the present study as the lack of knowledge about when it is appropriate to keep both languages separated and when it is appropriate to mix languages; this knowledge depends on the context of the language in use and the history of language socialization. Moreover, an important function of
}

control over their switches from one language to the other (according to the changes in the interlocutor, topics, and other contextual related switching factors) and those who have difficulty in maintaining or switching codes as required (p. 73). Similarly, Gumperz (1982), in his work on conversational code switching, noted that participants immersed in their conversation are often unaware of which language is used at any one time. He therefore suggested that language selection may be automatic and not readily subject to conscious recall. Similarly, Poulisse and Bongaerts (1994) defined "intentional" and "unintentional" switches in second language production, with the latter characteristically occurring without signs of hesitation or marked intonation. The study by Poulisse and Bongaerts (1994) was motivated by earlier findings by Giesbers (1989; cited in Poulisse and Bongaerts, 1994), who found that unintentional switches can be due to language interference. Similarly, Poplack (1985) distinguished "fluent" switches with smooth transitions and no hesitation from "flagged" switches, which are characterized by repetition, hesitation, into national highlighting and even metalinguistic commentaries.

The existence of unintended (involuntary) switches raises the question of to what degree these switches are related to individual differences in cognitive control and performance monitoring or problems in the control of activation of the non-target language. Explaining these switching patterns and their interindividual variability pose interesting problems for models of bilingual speech production (see review in La Heij, 2005; Kroll et al., 2006). Although this issue has not yet been studied, it is a promising research venue (see Prior and Gollan, 2011; Mas-Herrero et al., submitted; Soveri et al., 2011). Recent evidence indicates that bilinguals show better cognitive control than monolinguals in executive tasks, such as the Simon task (see for a recent review, see Bialystok et al., 2009). This advantage may be due to the more extensive engagement of executive functions since the early stages of language acquisition in infancy. In fact, cognitive control is likely required in bilinguals to switch appropriately between languages, avoiding interference and intrusions from the non-target language (Rodriguez-Fornells et al., 2002a, 2005, 2006; Abutalebi and Green, 2007; Moreno et al., 2008; Ye and Zhou, 2009). For example, Green's Inhibitory Control model (Green, 1986) features an inhibitory mechanism controlling the activation of the dominant language when using the weaker language. Thus, these demands faced by young bilinguals could drastically alter the cognitive control structure of bilingual speakers. However, interindividual differences in executive function may also lead to differences in switching behavior (Festman et al., 2010).

To summarize, there is a need to characterize the individual differences in language switching in multilingual communities through the use of different research approaches, ranging from sociolinguistic and educational to cognitive, psychological, and neuroscientific strategies (for a similar proposal, see Green, 2011).

metalinguistic awareness may be to assist the speaker to find and correct an utterance when a mistake occurs, monitoring when communication breakdowns and by analyzing which particular parts of an utterance should be targeted for revision, correction, or improvement (Marshall and Morton, 1978). Notice that this last definition directly involves monitoring and cognitive control processes, which may or may not be language specific. 


\section{THE PRESENT PROJECT}

The present study sought to develop a reliable self-assessment psychometric instrument to characterize individual differences in language switching, termed the bilingual switching questionnaire (BSWQ). Based on previous results (see above), we hypothesized that language switching could be decomposed into four constructs: (i) first-language (L1) switching tendencies (the tendency to switch from L2 to L1; L1-switch); (ii) second language (L2) switching tendencies (L2-switch), (iii) contextual switch (CS), which assesses the frequency of switches in particular situations or environments; and (iv) unintended switch (US), measuring the lack of awareness of the language switches. The first two factors (L1-switch and L2-switch) were intended to measure switching behavior related to linguistic factors (competence and proficiency in the target and non-target languages and semantic differences across languages; Grosjean, 1982; Poulisse and Bongaerts, 1994; Genesee et al., 2004). The CS construct was designed to measure switching patterns influenced by sociolinguistic factors related to specific situations, people, or topics in which the bilingual speaker usually switches (see above). The last factor, US, aimed to assess unintended language switching not explained by sociolinguistic or linguistic factors (Weinreich, 1953; Gumperz, 1982; Poplack, 1985; Giesbers, 1989; Poulisse and Bongaerts, 1994). In certain situations, however, different factors may simultaneously contribute to eliciting a particular language switch.

Finally, in order to assess the external validity of the individual differences scored with the new questionnaire, we evaluated the correlations between these measures and several psychometric and behavioral measures related first to the language history of the speaker (proficiency, onset of acquisition of each language, and language use) and, second, to cognitive control measures. More specifically, we evaluated the percentage of variance shared between the BSWQ and its factors with (i) quality of inhibitory function (assessed by the stop-signal reaction time (SSRT) in the stop-signal paradigm, Logan, 1995), (ii) stimulus-response interference (using the flanker Eriksen and Eriksen, 1974 task and the Stroop task), and (iii) verbal fluency, which is a well-known measure of executive function.

\section{MATERIALS AND METHODS PARTICIPANTS AND PROCEDURES}

A total of 582 Spanish-Catalan bilingual university students ( $75.1 \%$ women) with a mean age of 21.7 (3.5) years participated after providing their informed consent. The factorial analysis was performed on a final sample of 566 participants ( 16 participants were discarded due to missing data).

Most of the students were born in Catalonia (surrounding the Barcelona area) or had been raised there since early childhood). All participants had used Spanish and Catalan at home and/or at school during childhood. While newer developments have increased the use of Catalan in the educational system to approximately $90 \%$, the use of Catalan amounted to approximately $50 \%$ during the education of the present sample. In addition, exposure to Catalan television and radio programs guarantees enough exposure to Catalan even when Spanish was the only language spoken in the home environment. The results of a bilingual questionnaire of language use and self-assessment of proficiency
(Weber-Fox and Neville, 1996; used also in Rodriguez-Fornells et al., 2002a, 2005) revealed a rather balanced use of Spanish and Catalan (mean overall value $3.9 \pm 1.6$, rated on a sevenpoint scale with $1=$ Catalan only; $2=$ Catalan frequently, Spanish rarely; $3=$ Catalan majority with Spanish at least $1 / 4$ of the time; $4=$ Equal use of Catalan and Spanish; $5=$ Spanish majority with Catalan at least $1 / 4$ of the time; $6=$ Spanish frequently; Catalan rarely; and $7=$ Spanish only). The corresponding ratings for different life stages were infancy, $4.2 \pm 2.4$; childhood, $3.9 \pm 1.8$; adolescence, $3.9 \pm 1.6$; and adulthood, $3.8 \pm 1.5$. The statistical analysis showed a significant increase in the use of Catalan from infancy to adulthood $[F(3,1590)=22.6, P<0.001]$.

Regarding the use of Catalan and Spanish in different environments, approximately two-thirds of the participants indicated that they use both languages at the university $(63.50 \%)$ and in places other than home $(66.35 \%)$. The remaining third mainly or almost exclusively used one language, with a tendency toward more frequent use of Catalan.

The situation was found to be different at home, where approximately one third spoke solely Catalan $(29.36 \%)$ and another third solely Spanish (31.38\%). In the remaining households, both languages were spoken. In conclusion, in public places, the great majority of participants use both languages, whereas in private environments, one of the two languages is primarily used by most of the participants.

Self-assessment of language skills $(4=$ perfect, $3=$ good, $2=$ sufficient, $1=$ meager) showed very proficient values, although participants rated themselves significantly better in Spanish than Catalan [overall mean proficiency values: Spanish, $3.87 \pm 0.25$, Catalan, $3.73 \pm 0.46, t(543)=6.1, P<0.001]$. For all language skills tested, better ratings were obtained for Spanish than for Catalan (all $P<0.001$ ): comprehension, Spanish $3.98 \pm 0.14$, Catalan $3.91 \pm 0.32[t(543)=4.5]$; reading, Spanish $3.97 \pm 1.8$, Catalan $3.90 \pm 0.33[t(543)=4.3]$; speaking, Spanish $3.76 \pm 0.49$, Catalan $3.60 \pm 0.69[t(543)=4.4]$; and writing, Spanish $3.78 \pm 0.47$, Catalan $3.54 \pm 0.76[t(543)=6.8]$.

Finally, participants were asked to estimate the age of their initial exposure to each language. This estimation showed that the mean age of exposure to Spanish was earlier than for Catalan $[2.7 \pm 1.7$ versus $4.1 \pm 4.6, t(540)=6.6, P<0.001]$.

In summary, the present bilingual sample is very well-balanced in terms of language use and shows high proficiency levels in both languages. However, a small advantage is observed in Spanish proficiency, which is likely because exposure to Spanish occurred earlier than to Catalan in this sample. Although previous early studies of Spanish-Catalan code switching in the Barcelona region have shown that language mixing is not frequent (most likely for political reasons, see Calsamiglia and Tuson, 1984; Woolard, 1988), this tendency might have changed recently because of the efforts of the Catalan autonomic government to increase the presence of Catalan in the schools and media after 1975 (i.e., with the end of the dictatorship period).

\section{PSYCHOMETRIC AND BEHAVIORAL MEASURES}

Initially, a pool of 27 items was created to measure the following four constructs: Spanish-Switch (L1-Switch), Catalan-Switch (L2Switch), contextual switch (CS), and US. In the present study, we 
systematically used $L 1$ to refer to the Spanish language and $L 2$ for the Catalan language when discussing the constructed factors and items. Based upon the initial assessment of the items, their psychometric properties and initial exploratory factorial analysis, 12 of these items were ultimately selected (three for each construct). It is important to bear in mind that the main objective was to measure the four constructs mentioned (see final questionnaire in BSWQ Spanish Version in Appendix and its translation in BSWQ English Translation in Appendix). The entire analysis presented here is based on these 12 selected items.

The participants were required to evaluate the degree to which a behavior characterized his/her language switching habits. A fivepoint scale (1-5) was used, which quantified the frequency of the behavior described: never (1), rarely (2), occasionally (3), frequently (4), or always (5). Notice that the larger values on the index indicate more frequent switching behavior.

\section{OTHER PSYCHOMETRIC AND BEHAVIORAL MEASURES: Flanker-Stop combined task}

We used a modified variant of the Eriksen flanker task (Eriksen and Eriksen, 1974; adapted from Krämer et al., 2007) that required participants to respond to the central arrow in an array of five arrows (right/left hand response for right/left-directed arrow) and included an inhibitory-stop condition (adapted from Marco-Pallares et al., 2008). The four surrounding arrows were either compatible or incompatible with the central arrow, favoring performance errors. We presented 38.5\% compatible and 38.5\% incompatible trials. In $11.5 \%$ of the trials, we included a stop manipulation similar to a typical stop-signal paradigm (Band et al., 2003). In these trials, the central green arrow changed to red after a variable delay, signaling participants to inhibit their responses in these trials. Two different fixed stop-signal delays were employed (with equal probability), one yielding a low inhibitory rate $(180 \mathrm{~ms})$ and one yielding a high inhibitory rate $(70 \mathrm{~ms}$; Logan, 1995). The remaining $11.5 \%$ of the trials were change trials in which the central arrow changed its direction after $50 \mathrm{~ms}$, indicating to the subject that he/she should react with the other hand. Each stimulus array was presented in the middle of the screen. The stimulus duration was $300 \mathrm{~ms}$, and the stimulus onset asynchrony (SOA) was between 900 and 1100 ms (rectangular distribution; see Marco-Pallares et al., 2008).

The participants received several training trials to become acquainted with the task. They were encouraged to correct their errors in the go-trials as quickly as possible. The experiment was divided into three blocks, each composed of 208 trials, resulting in a total of 624 trials. We were able to extract several measures from this task that reflect inhibitory function, stimulus-response interference, and performance monitoring: the effect of incongruency on reaction time (the reaction time for correct responses in incompatible trials minus compatible trials), percentage of errors (errors in incompatible trials minus compatible trials), percentage of inhibited trials, and SSRT (see Band et al., 2003; we used the easy stop trials for the computation of the SSRT and the percentage of correctly changed trials). For the calculation of the SSRT, the reaction times of the correct trials during which a no stop-signal occurred were collapsed into a single distribution. The RTs were rank ordered, and the mean of the fastest $N$ trials was computed, where $N$ is the number of RTs in the distribution $(m)$ multiplied by the probability of responding at a given delay. This $n$th RT estimates the time at which the stop process finishes relative to the onset of the go-signal trials. For the estimation of the SSRT relative to the stop-signal onset, the stop-signal delay must be subtracted from this $n$th value (see Rodríguez-Fornells et al., 2002b).

\section{Stroop task}

We used a computerized version of the Stroop task (Stroop, 1935) that presented the words "blue," "green," and "red" in either a congruent or incongruent color, requiring the participant to press the button that was associated with the color in which the word was written. A total of 120 trials were presented (50\% incongruent), with 10 training trials at the beginning. Stimulus duration was $500 \mathrm{~ms}$, and the SOA varied randomly between 1500 and $2500 \mathrm{~ms}$. We computed the effect of incongruency on reaction time (reaction time for correct responses in incongruent trials minus congruent trials) and the percentage of errors (errors in incongruent trials minus congruent trials).

\section{Fluency task}

We used a phonological verbal fluency task in Spanish. The participants were required to write down as many words beginning with the letter $F$ as possible within $2 \mathrm{~min}$. The dependent variable was the number of written words. Only non-repeated words were scored as correct. Words that contained minor orthographic errors were considered to be correct.

\section{RESULTS \\ PRELIMINARY ANALYSES}

We computed univariate and multivariate descriptive statistics for the 12 items. The univariate descriptive statistics are shown in Table 1. The means ranged from 1.79 to 3.31 , whereas variance ranged from 0.7 to 1.57 . Polychoric correlation is advised when the distributions of ordinal items are asymmetric or show excessive kurtosis. If both indices are lower than one in absolute value, then Pearson correlation is advised (Muthén and Kaplan, 1985,

Table 1 | Univariate descriptive statistics for the items.

\begin{tabular}{|c|c|c|c|c|c|}
\hline Item & Mean & $\begin{array}{l}95 \% \text { Confidence } \\
\text { interval }\end{array}$ & Variance & Skewness & Kurtosis* \\
\hline 1 & 2.50 & $2.38-2.54$ & 0.87 & 0.47 & -0.14 \\
\hline 2 & 2.28 & $2.21-2.35$ & 0.70 & 0.17 & -0.46 \\
\hline 3 & 2.51 & $2.43-2.60$ & 1.07 & 0.15 & -0.79 \\
\hline 4 & 3.31 & $3.22-3.40$ & 1.35 & -0.37 & -0.75 \\
\hline 5 & 3.16 & $3.07-3.26$ & 1.38 & -0.32 & -0.84 \\
\hline 6 & 1.79 & $1.72-1.86$ & 0.77 & 1.00 & 0.36 \\
\hline 7 & 2.44 & $2.33-2.54$ & 1.57 & 0.46 & -0.92 \\
\hline 8 & 1.97 & $1.89-2.05$ & 0.87 & 0.81 & 0.06 \\
\hline 9 & 2.41 & $2.33-2.50$ & 1.02 & 0.45 & -0.44 \\
\hline 10 & 2.45 & $2.37-2.53$ & 0.98 & 0.33 & -0.49 \\
\hline 11 & 2.47 & $2.39-2.56$ & 1.10 & 0.43 & -0.40 \\
\hline 12 & 2.08 & $2.00-2.16$ & 0.92 & 0.78 & 0.25 \\
\hline
\end{tabular}

*Zero centered. Item 7 has been reversed. 
1992). In our data, the skewness and kurtosis indices were in the range of -1 to 1 .

The multivariate kurtosis coefficient was 188.129 , and the corresponding significance test $(Z=13.063 ; P<0.001)$ indicated that the multivariate distribution significantly deviated from a normal multivariate distribution. In this situation, a factor analysis method that assumes normal multivariate distribution is not advisable.

We computed the correlation matrix for the 12 items. The Kaiser-Meyer-Olkin values index was 0.716 , rendering the correlation matrix suitable for factor analysis.

\section{EXPLORATORY FACTOR ANALYSIS}

We used the FACTOR program to compute the exploratory factor (Lorenzo-Seva and Ferrando, 2006). The correlation matrix was factor-analyzed using minimum rank factor analysis (MRFA; Ten Berge and Kiers, 1991) followed by oblique direct oblimin rotation $(\gamma=0)$. The MRFA allows for computation of the proportion of common variance explained by each of the extracted factors. Because the test was developed to measure four dimensions, this was the number of factors that we extracted.

The proportion of common variance explained was $0.23,0.25$, 0.24 , and 0.15 for each factor, respectively, and the overall proportion of common variance explained was 0.86 . The root mean square of residuals (RMSR) was 0.0474 , whereas following Kelly's criterion (1935), the expected mean value of this index for an acceptable model was 0.0421 . Finally, the largest positive standardized residual was 2.69. These results allowed us to conclude that the proposed number of factors we wished to retain was, in fact, acceptable.

To assess the factor simplicity (Kaiser, 1974) of the rotated solution, we computed Bentler's (1977) Simplicity Index (S). This index assesses factor simplicity (with a value of 1 indicating maximal factor simplicity). The values for index $S(0.89)$ suggested high factor simplicity. Finally, the simplicity of the factor structure enabled us to identify the four factors as Switch to Spanish (L1S), Switch to Catalan (L2S), contextual switch (CS), and US. The oblique pattern matrix and the corresponding inter-factor correlation matrix are shown in Table 2 . Items 1,4 , and 9 were related to L1S. Items 2,5 , and 10 were related to L2S. Items 3, 11, and 12 were related to CS. Finally, items 6,7 , and 8 were related to US. $^{3}$

\footnotetext{
${ }^{3}$ A confirmatory Factor Analysis (CFA) instead of an Exploratory Factor Analysis (EFA) was conducted to test our assumptions about the underlying factorial structure and to assess whether our results and conclusions were due to the methodological approach (LISREL, Jöreskog and Sörbom, 2001). Multiple indices of fit were examined to evaluate the adequacy of the model. The Comparative Fit Index (CFI)
}

\section{Table 2 | Oblique exploratory factor solution.}

\begin{tabular}{|c|c|c|c|c|c|c|}
\hline \multicolumn{2}{|c|}{ Items } & \multirow{2}{*}{$\begin{array}{l}\text { L1S } \\
0.78\end{array}$} & \multirow{2}{*}{$\begin{array}{l}\text { L2S } \\
0.11\end{array}$} & \multirow{2}{*}{ CS } & \multirow{2}{*}{$\begin{array}{l}\text { US } \\
-0.24\end{array}$} & \multirow{2}{*}{$\begin{array}{l}\text { Communality } \\
0.74\end{array}$} \\
\hline 4 & When I cannot recall a word in Catalan, I tend to immediately produce it in Spanish & & & & & \\
\hline 1 & $\begin{array}{l}\text { I do not remember or I cannot recall some Catalan words when I am speaking in this } \\
\text { language }\end{array}$ & 0.76 & -0.20 & -0.15 & 0.15 & 0.80 \\
\hline 9 & $\begin{array}{l}\text { Without intending to, I sometimes produce the Spanish word faster when I am speaking in } \\
\text { Catalan }\end{array}$ & 0.73 & -0.04 & -0.01 & 0.23 & 0.76 \\
\hline 5 & When I cannot recall a word in Spanish, I tend to immediately produce it in Catalan & 0.16 & 0.88 & 0.18 & -0.29 & 0.92 \\
\hline 10 & $\begin{array}{l}\text { Without intending to, I sometimes produce the Catalan word faster when I am speaking in } \\
\text { Spanish }\end{array}$ & -0.09 & 0.75 & -0.13 & 0.26 & 0.80 \\
\hline 2 & $\begin{array}{l}\text { I do not remember or I cannot recall some Spanish words when I am speaking in this } \\
\text { language }\end{array}$ & -0.15 & 0.68 & -0.05 & 0.10 & 0.65 \\
\hline 11 & There are situations in which I always switch between the two languages & -0.10 & -0.08 & 0.92 & -0.04 & 0.80 \\
\hline 12 & There are certain topics or issues for which I normally switch between the two languages & 0.09 & 0.00 & 0.61 & 0.09 & 0.50 \\
\hline 3 & $\begin{array}{l}\text { I tend to switch languages during a conversation (for example, I switch from Spanish to } \\
\text { Catalan or vice versa) }\end{array}$ & 0.10 & 0.12 & 0.54 & 0.26 & 0.62 \\
\hline 7 & When I switch languages, I do it consciously & -0.05 & 0.00 & -0.02 & -0.51 & 0.42 \\
\hline 8 & $\begin{array}{l}\text { It is difficult for me to control the language switches I introduce during a conversation (e.g., } \\
\text { from Catalan to Spanish) }\end{array}$ & 0.10 & 0.14 & 0.28 & 0.49 & 0.55 \\
\hline \multirow[t]{6}{*}{6} & $\begin{array}{l}\text { I do not realize when I switch the language during a conversation (e.g., from Catalan to } \\
\text { Spanish) or when I mix the two languages; I often realize it only if I am informed of the } \\
\text { switch by another person }\end{array}$ & 0.01 & 0.14 & 0.26 & 0.49 & 0.52 \\
\hline & Proportion of common explained variance & 0.23 & 0.25 & 0.24 & 0.15 & - \\
\hline & Inter-factor correlation matrix & L1S & L2S & CS & & \\
\hline & L2S & -0.14 & & & & \\
\hline & CS & 0.27 & 0.33 & & & \\
\hline & US & 0.13 & 0.20 & 0.28 & - & \\
\hline
\end{tabular}

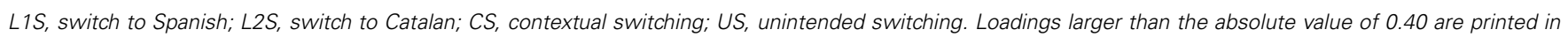
bold face. 
The inter-factor correlation matrix showed moderate correlations (from 0.14 to 0.33 in absolute values). Only the correlation between L1S and L2S was negative, indicating that a greater tendency to switch language in one direction was associated with a diminished tendency to switch in the opposite direction. In our sample, responders seemed to be slightly more dominant in one or the other language.

\section{DESCRIPTIVE STATISTICS OF SCALES}

The scores for each individual $(N=566)$ on scales L1S, L2S, CS, and US were then computed by raw addition of the corresponding item scores. Note that item 7 was conveniently reversed. Because all of the factors were correlated, an overall score could be obtained by the raw addition of all item scores. Even if factors L1S and L2S were slightly negatively correlated, the score in each indicates the degree of switching from one language to the other, so the addition of both scores for an overall score is still meaningful. This overall score was named overall switching (OS).

The descriptive statistics for the scales and the internal consistency (alpha coefficient) of scales L1S, L2S, CS, US, and OS were then computed. The values of these coefficients, printed in Table 3, show that the scale reliabilities are acceptable, with the exception of scale US. In reality, because each scale contains a small number of items, high reliabilities were not expected. Factor scores were

assesses the lack of fit as estimated by the non-central chi-square distribution of a target model compared to a baseline model. The Goodness-of-Fit Index (GFI) is an index of absolute fit that is related to the relative amount of the observed variances and covariances accounted for by the hypothesized model. Hu and Bentler (1999) recommended a cutoff value close to 0.95 for these fit indices. The root mean square error of approximation (RMSEA) is based on the analysis of residuals and compensates for the effects of model complexity. Hu and Bentler (1999) recommended a cutoff close to 0.06 . The values obtained for these indices in our study were $\mathrm{CFI}=0.99$, GFI $=0.99$, and RMSEA $=0.045$. Thus, we can conclude that the data perfectly fit the hypothesized four-factor model. In addition, our results and conclusions are independent of the methodological approach used (i.e., EFA versus CFA). However, as this is the first analysis to be published with the SWQ tests, we think that is it more coherent to use an EFA approach. If other researchers aim to replicate our results in other samples, then a CFA would be better justified.

Table 3 | Descriptive statistics for scale and factor scores.

\begin{tabular}{lcccc}
\hline Scales & Mean & SD & \multicolumn{2}{c}{ Reliability } \\
\cline { 4 - 4 } & & & Alpha & Cl 90\% \\
\hline L1S & 7.3 & 1.7 & 0.75 & $(0.72-0.78)$ \\
L2S & 8.3 & 2.2 & 0.74 & $(0.71-0.77)$ \\
CS & 6.8 & 2.3 & 0.75 & $(0.72-0.78)$ \\
US & 7.0 & 2.2 & 0.58 & $(0.52-0.63)$ \\
OS & 29.3 & 6.3 & 0.74 & $(0.71-0.77)$ \\
FACTOR SCORES & & & \\
L1S & & & 0.84 & $(0.82-0.86)$ \\
L2S & & & 0.92 & $(0.88-0.90)$ \\
CS & & & 0.84 & $(0.82-0.86)$ \\
US & & & 0.72 & $(0.69-0.75)$ \\
\hline
\end{tabular}

L1S, switch to Spanish; L2S, switch to Catalan; CS, contextual switch; US, unintended switch; OS, overall switch. estimated using Barrett's factor scores, and the corresponding reliabilities are also printed in Table 3. Note that three reliabilities (corresponding to factors L1S, L2S, and CS) are larger than 0.80 , suggesting that factor scores should be preferred over raw scale scores. In addition, the reliability of factor US is larger than 0.70 .

The mean and SD of each raw scale is also printed in Table 3. For the overall raw score (OS), the Kolmogorov-Smirnov test $(Z=1.25$ and $P=0.087)$ indicated that the distribution of scores did not significantly differ from a normal distribution. Thus, the participants' scores were normally distributed. However, it is important to note that because a large sample was used $(N=566)$, differences between the distribution of participants' scores and a normal distribution were not expected to be statistically significant.

Finally, to graphically represent the switching patterns for a participant or to compare samples, in Figure 1A, we have plotted the mean values of the present sample on four axes, each representing a specific factor (with scores ranging from 3 to 15 in this particular case). This graphic can be useful for describing different types of samples. In Figure 1B, we depict the raw scores of one of the participants.

\section{CORRELATIONS BETWEEN THE BSWO AND L1/L2 PROFICIENCY AND LANGUAGE USE MEASURES}

The pattern of correlations between language proficiency measures, age of acquisition (AOA) of both languages and language use is presented in Table 4. For the onset of language acquisition and proficiency, a very congruent pattern emerged. If Spanish (L1) was acquired later, an increase in switches to Catalan is observed. The reverse pattern was found if the age of Catalan acquisition was later. An analogous pattern is observed for proficiency (averaging comprehension, reading, speaking, and writing scores). A greater proficiency in a target language is correlated with fewer switches to the other language.

The greatest correlations are observed for the language use evaluation of Spanish and Catalan across the lifespan (subtraction score). The predominant use of Spanish is correlated with increased switching to L1 and decreased switching to L2.

In summary, the present pattern of correlations clearly reflects the validity of factors L1S and L2S as measures of language switching for linguistic reasons (competence and proficiency). Importantly, notice that the OS measure did not correlate with proficiency measures, AOA or language use (likely because the effects of L2S and L1S cancel each other out).

\section{CORRELATIONS BETWEEN THE BSWO AND COGNITIVE CONTROL VARIABLES}

The pattern of correlations observed between the BSWQ factors and the overall score is illustrated in Table 5. It is important to note that a large sample was used in the present study, and thus, despite being significant, the magnitude of some correlations (and variance shared) is very small.

The significant correlation observed between L1S and Fluency indicates that a larger number of switches is expected if fluency in L1 is greater. This result is important because fluency was evaluated in Spanish. Thus, more switches into L1 are expected if the vocabulary is better developed in L1 than in L2. Indeed, 


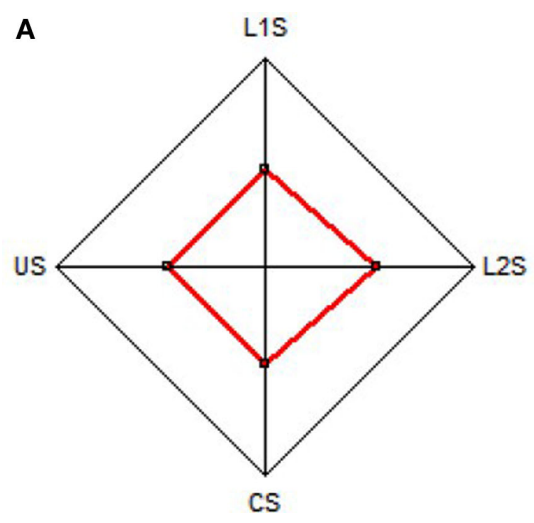

FIGURE 1 | (A) Representation of the mean values observed in the overall Catalan-Spanish sample for the switching tendencies in each factor (larger values represent greater switching). Larger L1-L2 switching was observed, although it was essentially equal for $L 1$ and

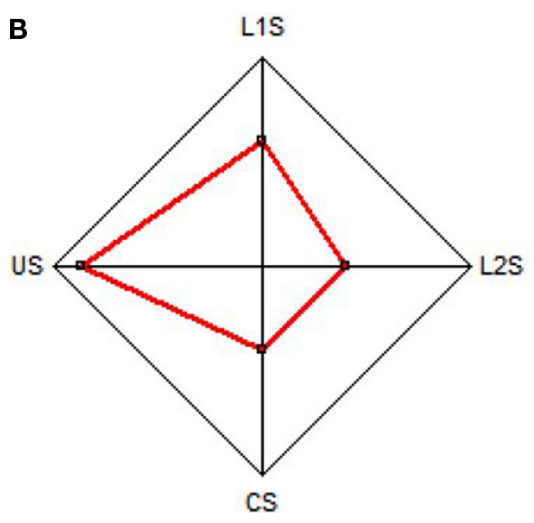

L2 in the overall sample. Each axis represents a value between 3 and 15. (B) The diagram represents an actual participant with strong US switching into L1. Essentially, no switching is observed in the L1 or contextual switch.
Table 4 | Correlations between the BSWO global scores and proficiency/language use self-assessment scores.

\begin{tabular}{|c|c|c|c|c|c|}
\hline & os & L1S & L2S & CS & US \\
\hline Age onset of L1 & & $-0.214^{*}$ & $0.254^{*}$ & & \\
\hline Age onset of L2 & & $0.345^{*}$ & $-0.286^{*}$ & & \\
\hline L1 proficiency & & $0.207^{*}$ & $-0.347^{*}$ & & $-0.099^{+}$ \\
\hline L2 proficiency & & $-0.471^{*}$ & $0.357^{*}$ & & \\
\hline Language use (L2-L1) & & $0.622^{*}$ & $-0.570^{*}$ & & \\
\hline
\end{tabular}

$N=536 . S$, overall switch; L1S, switch to Spanish; L2S, switch to Catalan; CS, contextual switch; US, unintended switch. ${ }^{+} P<0.05 ;{ }^{*} P<0.001 . L 1$ and $L 2$ proficiency: averaging the global scores of rated skills in comprehension, reading, speaking, and writing. Language use: overall language use across different life periods assessed on a seven-point scale; low scores indicate predominance of Catalan ( $L 2)$ use, and high scores indicate $L 1$ predominance. Empty cells show non-significant effects.

Fluency positively correlates with the tendency to use Spanish $[r$ $(529)=0.14, P<0.001]$. In summary, a portion of this effect could be due to the dominance of L1 Spanish.

As expected, however, the US factor showed a negative correlation with Fluency, indicating that the production of more words is associated with less switching and most likely better cognitive control. The positive correlation with the stop-signal task (SSRT) indicates that participants with less US tendencies needed less time to inhibit responses on stop trials. Because US may reflect the uncontrolled activation of lexical candidates from the non-target language, its relation to inhibitory abilities is expected in order to increase the suppression of erroneous responses.

A similar interpretation can be made for the correlations between L2S (switching to Catalan) and Stroop interference and L2S and Fluency. Greater L2 switching is associated with lower fluency scores and more interference in the Stroop task (reaction time and erroneous incongruence measures). It is also important to highlight that no differences were observed between the Flanker task measures and any of the BSWQ factors.
Table 5 | Correlations between the BSWO global score and its factors with external variables.

\begin{tabular}{|c|c|c|c|c|c|}
\hline & os & L1S & L2S & cs & US \\
\hline \multicolumn{6}{|l|}{ FLANKER } \\
\hline \multicolumn{6}{|l|}{$\mathrm{RT}$ incongruence } \\
\hline \multicolumn{6}{|l|}{ STROOP } \\
\hline $\mathrm{RT}$ incongruence & & & $-0.112^{+}$ & & \\
\hline$\%$ errors incongruence & & & $-0.115^{+}$ & & \\
\hline
\end{tabular}

\section{STOP-SIGNAL}

(SSRT)

$0.101^{+}$

\section{FLUENCY}

Number of words

$0.105^{+}-0.157^{*}$

$-0.125^{*}$

OS, overall switch; L1S, switch to Spanish; L2S, switch to Catalan; CS, contextual switch; US, unintended switch; Flanker $(N=525)$ : reaction time incongruence effect; Stroop ( $N=491)$ : reaction time incongruence effect and percentage of errors incongruence effect; stop-signal ( $N=491)$ : stop-signal reaction time for the easiest delay (SSRT); fluency ( $N=533$ ): number of words produced that begin with a specific letter; ${ }^{+} P<0.05 ;{ }^{*} P<0.001$. Empty cells show non-significant effects.

Because of the possible differences in the bilingual population, we explored the previous pattern of correlations according to the AOA onset for both languages. First, we excluded from the analysis bilinguals who had learned one of the languages after the age of 10 years to reduce the variability of the sample. It is important to note that in most of the cases, in Catalonia, both languages are acquired during the schooling period due to bilingual educational policies. Second, in the remaining sample, we created three groups of bilinguals according to the AOA for each language: Catalan-Spanish simultaneous bilinguals (AOA Spanish $\leq 3$ years; AOA Catalan $\leq 3$ years), Catalan-Spanish bilinguals (AOA Catalan $\leq 3$ years; AOA Spanish: $\geq 5$ years) and Spanish-Catalan bilinguals (AOA Spanish $\leq 3$ years, AOA Catalan $\geq 5$ years; see Table 6 for the characterization of the language use variables and proficiency of the sample). As can be seen in Table 6, significant 
Table 6 | Correlation analysis for the BSWO and executive tasks according to three different bilingual groups and based on the age of acquisition for L1/L2.

\begin{tabular}{|c|c|c|c|c|}
\hline & $\begin{array}{l}\text { Simultaneous } \\
\text { bilinguals } N=268\end{array}$ & $\begin{array}{l}\text { Catalan-Spanish } \\
\text { bilinguals } N=75\end{array}$ & $\begin{array}{l}\text { Spanish-Catalan } \\
\text { bilinguals } N=111\end{array}$ & $\begin{array}{l}\text { Overall sample } \\
\text { (from Table 4) }\end{array}$ \\
\hline \multicolumn{5}{|l|}{ PROFICIENCY AND LANGUAGE USE } \\
\hline Age onset of Catalan & $2.2 \pm 0.4$ & $2.0 \pm 0.11$ & $5.5 \pm 1.2^{+++}$ & \\
\hline Spanish proficiency & $3.9 \pm 0.2$ & $3.7 \pm 0.33$ & $3.9 \pm 0.25^{+++}$ & \\
\hline Catalan proficiency & $3.9 \pm 0.2$ & $3.9 \pm 0.21$ & $3.7 \pm 0.43^{+++}$ & \\
\hline \multicolumn{5}{|l|}{ BSWO } \\
\hline L1S & $8.1 \pm 2.3$ & $6.4 \pm 2.2$ & $9.0 \pm 2.4^{+++}$ & \\
\hline L2S & $7.9 \pm 2.2$ & $9.9 \pm 2.0$ & $7.2 \pm 2.5^{+++}$ & \\
\hline CS & $7.1 \pm 2.6$ & $6.9 \pm 2.1$ & $7.1 \pm 2.7$ & \\
\hline US & $6.0 \pm 2.3$ & $6.4 \pm 2.3$ & $6.5 \pm 2.6$ & \\
\hline Fluency - L1S & -0.06 & $0.22^{*}$ & 0.14 & $0.11^{+}$ \\
\hline Fluency - L2S & $-0.14^{+}$ & $-0.31^{++}$ & -0.06 & $-0.16^{+++}$ \\
\hline Fluency - US & $-0.17^{++}$ & $-0.22^{*}$ & -0.05 & $-0.13^{++}$ \\
\hline
\end{tabular}

In the proficiency/language use and BSWO measures, an ANOVA has been conducted with language group as a between-subjects factor (superscript ${ }^{+++}$indicates significant differences between groups at $P<0.001$ ). L1S, switch to Spanish; L2S, switch to Catalan; CS, contextual switch; US, unintended switch; Stroop, reaction time incongruence effect and percentage of errors incongruence effect; stop-signal, stop-signal reaction time for the easiest delay (SSRT); fluency, number of words produced that begin with a specific letter; correlation superscripts: ${ }^{*} P<0.07 ;{ }^{+} P<0.05 ;{ }^{++} P<0.01 ;^{+++} P<0.001$.

differences were observed for AOA Spanish and Catalan across the three groups of proficiency in Catalan and Spanish and history of language use. Notice, however, that the mean self-assessed proficiency levels are close to the maximum value in all groups (maximum score 4), even in the non-simultaneous groups. Although the groups were created according to the AOA for both languages, very similar groups could be created on the basis of other variables such as proficiency level and language use. Notice that the correlation between these variables is highly significant: AOA Catalan and Catalan proficiency $(r=-0.4, P<0.001$, later exposition to Catalan, decreased proficiency in Catalan) and AOA Catalan and Language use $(r=0.53, P<0.002$, delayed onset of Catalan exposition, greater use of Spanish).

Moreover, in Table 6 we can see the group differences in the BSWQ variables. For the L1-L2 switches, large differences were observed across groups. The Catalan-Spanish group tended to switch to Catalan more often, whereas the Spanish dominant group switched more often to Spanish. No differences were observed for the mean number of contextual switches. Instead, the Spanish-Catalan and the Catalan-Spanish groups showed a tendency for larger amount US switches. When the simultaneous bilingual group was compared directly to the SpanishCatalan group, a marginal statistical trend was observed $[t$ $(372)=-1.74, P<0.08]$. After pooling both non-simultaneous groups (Spanish-Catalan and Catalan-Spanish groups), a significant effect appeared compared to the simultaneous bilingual group $[t(445)=1.98, P<0.05]$. Thus, the bilingual simultaneous group showed fewer US.
In Table 6, we compare the correlations between the selected cognitive control variables highlighted in Table $\mathbf{5}$ across the different proficiency groups. First, the most reliable effects across groups were observed for Fluency (number of words) and, specifically, for the relation between fluency L2S and US. However, these effects were significant only in the Catalan-Spanish and simultaneous bilingual groups. No significant effects of fluency were observed for the Spanish-Catalan group. This result is important because it clarifies the correlation that was observed between $\mathrm{L} 2 \mathrm{~S}$ and Fluency in the full sample. The negative correlation indicates that greater cognitive control (measured by fluency) prevents switches to the L2 in simultaneous and L2-dominant bilinguals. This result is not observed in the Spanish dominant group because the tendency to switch to Catalan is largely reduced.

For the relationship between SSRT and US, the same correlation was observed across the three groups (range, 0.07-0.08), even though they were non-significant due to the reduced sample size. The relationships between the two Stroop measures and the BSWQ seemed less reliable and more variable across the different samples.

\section{DISCUSSION}

In the present study, we aimed to psychometrically characterize individual differences in language switching patterns observed in bilinguals. To our knowledge, this is the first attempt to create a self-assessment measure to evaluate individual differences in language switching. Although large differences in language switching have been previously reported between individuals and in bilingual 
communities, a measure such as the present one helps to systematize these differences. Four factors were validated and assessed using the BSWQ: (i) L1-Switch, which measures the tendency to switch to Spanish (L1); (ii) L2-Switch, which measures the tendency to switch to L2 (Catalan); (iii) contextual switch (CS), which indexes the frequency of switches introduced usually in a particular situation or environment; and (iv) US, which measures the lack of awareness for language switches.

As we expected, the first two factors, L1S and L2S, were associated with switching behavior induced by linguistic needs. The large and robust correlations observed between language use, L1S and L2S reflect the fact that these types of language switches are mainly due to linguistic needs (i.e., to fill a lexical gap in a conversation with a word from the language not in use or to find a better word to convey the message in the other language; Grosjean, 1982; Poulisse and Bongaerts, 1994; Genesee et al., 2004). The correlations of L1S and L2S with proficiency and the onset of language acquisition also clearly point in this direction (see Table 4).

The factor CS was intended to reflect switching patterns influenced by external sociolinguistic/pragmatic factors. In contrast to the externally triggered nature of the CS, the factor US measures US that cannot be explained by sociolinguistic or merely linguistic factors (Weinreich, 1953; Gumperz, 1982; Poplack, 1985; Giesbers, 1989; Poulisse and Bongaerts, 1994).

\section{INDIVIDUAL DIFFERENCES IN LANGUAGE SWITCHING AND COGNITIVE CONTROL}

The present results provide initial support for a relationship between self-perceived language switching tendencies and cognitive control, thus echoing a theme introduced by Bialystok et al. (2009) on the basis of laboratory experiments. Some small but significant and reliable relationships for the full sample (see Table 5) and across bilingual groups (see Table 6) were encountered between factor US, the latency of inhibitory processes and verbal fluency scores. This result clearly indicates a link between cognitive control and individual differences in factor US. In addition, when the sample was divided into simultaneous and non-simultaneous bilinguals, fewer US were observed in the simultaneous group; this result once again points to increased cognitive control for bilinguals who are exposed to both languages very early in life.

In a similar fashion, Soveri et al. (2011) used a multiple regression approach in a group of high-fluency Finnish-Swedish bilinguals to study the effects of individual differences in language switching (using the BSWQ) on several executive tasks. Interestingly, the amount of language switching predicted mixing costs in a set-shifting task: greater everyday switching was associated with reduced mixing costs, especially in the number of erroneous responses. Because this executive measure is supposed to reflect the sustained, top-down regulation, and monitoring of alternative or competing task-schemas in order to efficiently react to changes in the task, the authors considered that the relationship could be associated with the long-term effects of language switching on executive function.

However, these cited findings are contradictory to those reported in Prior and MacWhinney (2010), who found a bilingual advantage in switching costs but not in mixing costs in a study with young adults (see also Prior and Gollan, 2011 for similar findings).
Moreover, Mas-Herrero et al. (submitted) recently compared a fluent Spanish-Catalan group of bilinguals with a monolingual group in a language switching paradigm. Interestingly, the authors found that increased contextual everyday switching (measured using the BSWQ) predicted reduced switching costs in the language switching paradigm. Thus, this result converges with the previous results from Soveri et al. (2011) and strengthens the relationship between habitual language switching and cognitive control processes (see also Prior and Gollan, 2011).

An important caveat, given that the magnitude of the relationship between language switching and cognitive control was small in the present investigation, is that the present findings should be interpreted with caution. The small magnitude of the effects may explain why recent literature on the relationship between cognitive control and bilingualism has been divergent (Morton and Harper, 2007; Carlson and Meltzoff, 2008; Festman et al., 2010). In a recent study, Hilchey and Klein (2011) reviewed several investigations that compared the performances of monolingual and bilingual groups on non-linguistic interference tasks to evaluate the validity of the claim that bilinguals have advantages in inhibitory control. The authors' conclusions shed serious doubts about the previous findings regarding bilingual advantages in cognitive control, especially for interference tasks (e.g., the flanker or Simon paradigms). Similarly, Gollan et al. (2011) showed a rather small contribution of cognitive control in bilingual language processing. Two groups of younger and older bilinguals were evaluated using cognitive control (the flanker task) and fluency verbal tasks, which specifically focused on scoring cross-language intrusions. Interestingly, only the older bilingual group showed a relationship between cognitive control (as measured by the incongruency error effect in the flanker task) and the number of cross-language errors, as this effect is absent in the younger sample. Although this finding is very interesting because it links declines in cognitive control during aging and cross-language bilingual interference, it also indicates that younger bilinguals likely did not show this effect because they were performing at ceiling levels. This reason may also be why we did not encounter a clear relationship between the flanker incongruency effect and language switching across languages in the present study.

Another important consideration is that in the present study, we used a flanker-stop task with a large amount of trials in each condition and a very fast SOA (900-1100 ms; including the stop task, a total of 624 trials were administered per participant; Krämer et al., 2007). In other studies, a much smaller number of trials was used, emphasizing individual differences during the early stages of performing a new task instead of stable differences in cognitive control after task-practice or habituation to the experimental setup (see Hilchey and Klein, 2011 for a review). As the authors note, the bilingual advantage to conflict resolution in adults and the elderly tends to vanish as a function of the number of trials to which the participants have been exposed (Hilchey and Klein, 2011).

\section{AWARENESS AND ERROR MONITORING IN LANGUAGE SWITCHING}

Interestingly, two of the factors identified, Contextual and US, appear to share a common facet, namely, that in many cases, contextual switches might also occur without explicit awareness of the language switch. Although some contextual switches appear to be 
under the speaker's conscious control (Kroll et al., 2006) and may be driven by pragmatic and social considerations, in other cases, such as when a switch is triggered by a cognate word (Clyne, 1967, 1972; Broersma, 2009), the switch will not be consciously planned. It is also of note that the language selection and on-line adjustments shown by high proficiency bilinguals when interacting with a stranger who has no knowledge of his/her language proceeds very smoothly and flexibly, and in some cases even unconsciously (Gumperz, 1982; Petitto et al., 2001; Comeau et al., 2003; Genesee et al., 2004). Although the subtle and probably subliminal cues that drive this intriguing process are far from being understood, it is important to distinguish this type of contextually triggered switch from the unintended type that is captured by the US factor. The latter refers to unintended and inappropriate switches, reflecting a lack of metalinguistic awareness and similarities with accidental speech errors (Weinreich, 1953; Poplack, 1985; Giesbers, 1989; Poulisse and Bongaerts, 1994). These errors might be related to cognitive control abilities and their interactions with language functions rather than to contextual-situational factors. Indeed, this factor was better correlated with the cognitive control variables and was more reliable across groups in the present study (see Table 6).

The differences between contextual and US might involve different executive control processes because one process is triggered externally (CS), whereas the other has internal origins (US). Thus, these psychometric factors reflect the important distinction between behaviors guided by internal processes and behaviors stimulated by the environment (see discussion in RodríguezFornells et al., 2002b). Contextual switches might appear because subtle contextual cues from the environment impact the activation of specific language-based schemas that immediately trigger the activation of lexical items in the non-target language, thereby increasing competition (Green, 1986; Norman and Shallice, 1986; Cooper and Shallice, 2006). For example, typically, bilinguals immediately change the language of their conversation if a third person joins the conversation and the speaker knows that the joiner does not speak that language. Although this process seems to proceed automatically and in a very effortless way, further studies in naturalistic environments are needed to investigate its automaticity when triggered by an external or internal cue, the degree of awareness about this process and the resources that are needed (switch costs).

In this regard, the present distinction between CS and US may be similar to the dichotomy of voluntary/involuntary switches recently described by Gollan and Ferreira (2009). These authors expanded on previous work regarding voluntary switching costs (Arrington and Logan, 2004) to demonstrate the differences between voluntary and involuntary language switches under laboratory conditions (see also Yeung, 2010). The involuntary switches were triggered by specific task instructions to switch the language (cued-switches, which are similar to a method used by Meuter and Allport, 1999), while the voluntary switches were spontaneously induced by requesting that the participants answer in the language of their choice, either Spanish or English. Although the involuntary/cued-switches in Gollan and Ferreira (2009) and the CS factor in the present investigation show some resemblance, it is important to bear in mind that cued language switching tasks used in the laboratory are very unnatural and probably do not reflect the complex dynamics of bilingual communication in mixing contexts. On the other hand, US cannot be equated with the voluntary switches described by Gollan and Ferreira (2009). The best characterization of natural language switching for the US factor is probably a lack of explicit intention to switch. Indeed, a language switch could be internally elicited, but it could also be absolutely involuntary (e.g., a problem with language interference in which the non-target lexical candidate is selected). Rather, "voluntary switches" as defined by Gollan and Ferreira (2009) might be similar to the switches related to linguistic needs (i.e., L1S and L2S), which in some cases could be voluntarily driven and triggered because of differences in proficiency levels.

To better understand unintended and involuntary language switches, ecologically valid and natural situations in which switches can be categorized and separately studied need to be created. Kootstra et al., 2009; see also Kootstra et al., 2010) recently introduced an interesting method to investigate the natural language alignment of the interactions of two or three participants engaged in natural conversation. Their method presents a very promising venue in which to study the switching costs associated with different types of language switches in bilinguals. An interesting experiment would be to create interactions between participants with different language switching tendencies and to study the dynamics of the resulting conversations.

When distinguishing Contextual and US within the context of cognitive control models (e.g., Norman and Shallice, 1986; Shallice, 2004), it is important to consider how bilinguals switch languages and why in some cases these switches bypass awareness. The implementation of a monitoring device in speech production and bilingual models has been postulated by different authors (e.g., a language switching on/off mechanism, McNamara and Kushnir, 1971; a monitoring system, Albert and Obler, 1978; Comparator system, Lipski, 1978 and Sridhar and Sridhar, 1980; see for an interesting and recent review, Nozari et al., 2011 and neuroscientific evidences, Möller et al., 2007). The question remains, how can this type of error monitoring system be implemented, and how do bilinguals evaluate the occurrence of Contextual and US? Cognitive control in this particular situation may also depend on the degree of separation or segregation of target and non-target language representations in the brain (for different proposals, see Green, 1998; Grosjean, 1998; De Bot, 2004) and how top-down and local activation and inhibition mechanisms impact the overall activation level of the target and non-target languages in use (see Green, 1986; Li and Farkas, 2002; Rodriguez-Fornells et al., 2006). Thus, additional work in this area is needed to better understand the cognitive control architecture involved in bilingual language switching.

\section{LIMITATIONS OF THE PRESENT STUDY}

Finally, it is important to comment on several limitations of the present study, which was exclusively aimed at developing a selfassessment measure of individual differences in language switching patterns. One of the main caveats is that we did not provide an external, independent variable for language switching or code switching behavior (see Gullberg et al., 2009). For example, it would have been important to gather information on real language 
switching behavior in conversations between bilinguals (e.g., using the procedure described in Kootstra et al., 2009, 2010), the number of voluntary language switches used when naming simple pictures (see Gollan and Ferreira, 2009) or administrating the BSWQ questionnaire to a third person (relatives or friends of the evaluated person) in order to correlate self- and informant-assessments of language switching. Further research in this direction will be needed to validate the present findings.

However, at least three recent studies may provide some validity to the use of self-reported measures of language switching in daily life such as the BSWQ. First, in an interesting study, Prior and Gollan (2011) used a self-reported measure of language switching in two groups of bilinguals living in the United States, Spanish-English and Mandarin-English speakers. The groups indeed differed in the amount of language switching that occurred in their daily conversations, with a greater switching tendency in the Spanish-English group. This pattern was expected, considering that Spanish is a language that is more common and accessible than Mandarin. This finding validates the use of self-report measures to characterize bilingual switching patterns in communities (Ritchie and Bhatia, 2006). Moreover, Prior and Gollan (2011) used a nonlinguistic language switching task to provide a direct measure of non-language and language switching and mixing costs. When compared to a monolingual group, only the Spanish-English bilingual group, which reported larger everyday language switching tendencies, showed a reduced switching cost (either for the nonlinguistic or the linguistic task). This result is interesting because it is the first one to suggest a specific link between self-reported individual differences on language switching in daily life and a specific advantage to cognitive control, which improved general switching abilities. However, it is important to highlight that in this study, the Spanish-English group was more balanced in terms of proficiency in both languages, making it more difficult to rule out the possible contribution of proficiency in the effects encountered. Indeed, disentangling the effects of proficiency and language switching tendencies will be difficult because in some populations, these measures are correlated (Gollan and Ferreira, 2009).

Second, as noted above, Soveri et al. (2011) also found that everyday language switching (using the BSWQ) predicted mixing costs in a set-shifting task. Third, in a recent article, Festman et al. (2010) divided a sample of Russian-German bilinguals into

\section{REFERENCES}

Abutalebi, J., and Green, D. W. (2007). Bilingual language production: the neurocognition of language representation and control. J. Neurolinguistics 20, 242-275.

Albert, M., and Obler, L. (1978). The Bilingual Brain: Neuropsychological and Neurolinguistic Aspects of Bilingualism. London: Academic Press.

Ameel, E., Storms, G., Malt, B. C., and Sloman, S. A. (2005). How bilinguals solve the naming problem. J. Mem. Lang. 53, 60-80

Arrington, C. M., and Logan, G. D. (2004). The cost of a voluntary task switch. Psychol. Sci. 15, 610-615.

language switchers and non-switchers based on the amount of switches observed in a bilingual picture naming task. Interestingly, those who were classified as switchers using this task also showed more involuntary language switches in a simple verbal fluency task. This task was conducted under more natural circumstances and used a bilingual interview in which the target language was altered every $5 \mathrm{~min}$. Importantly, the switch group obtained worse scores on several neuropsychological tests of executive function. These results also indicate that natural individual differences in language switching can be observed and can be related to a reduced cognitive control that likely diminishes the ability of certain bilinguals to prevent cross-language interference. Because the language switches in that study were in most cases involuntary, it may be interesting to relate these findings to individual differences in the US factor identified in the BSWQ. This result is consistent with one of the reliable findings in the present study, the significant correlation observed between cognitive control measures and the US factor. Better cognitive control (based on Fluency or SSRT) was associated with a diminished number of US (see Table 6) in the simultaneous and Catalan-dominant bilinguals.

Future studies will be needed on this topic to better characterize individual differences in code switching across different groups of bilinguals (Green, 2011) and to determine which factors in bilingualism are critical for explaining the long-term effects in cognitive control that are observed in some bilingual groups (Bialystok et al., 2009).

\section{ACKNOWLEDGMENTS}

We would like to thank E. Camara, T. Cunillera, D. Cucurell, and J. Marco-Pallares for their help during the acquisition of the present data, which were gathered in the context of a large neurogenetic study funded by a grant from the Volkswagen-Foundation (awarded to Thomas F. Münte and Antoni Rodriguez-Fornells). In addition, Antoni Rodriguez-Fornells has been supported by a grant from the Spanish (PSI2008-03901) and the Catalan Governments (SGR 2009 SGR 93). Ulrike M. Krämer and Thomas F. Münte have been supported by the Deutsche Forschungsgemeinschaft (DFG). Thomas F. Münte is also supported by German Federal Ministry of Science (BMBF). The present project benefited from the discussions and support from E. Mas-Herrero, R. de Diego Balaguer, and M. Laine.

Bhatia (San Diego: Academic Press), 627-688.

Bialystok, E., Craik, F. I. M., Green, D., and Gollan, T. H. (2009). Bilingual minds. Psychol. Sci. Public Interest 10, 89-129.

Bowerman, M., and Choi, S. (2001). "Shaping meanings for language: universal and language-specific in the acquisition of spatial semantic categories," in Language Acquisition and Conceptual Development, eds M. Bowerman and S. C. Levinson (Cambridge: Cambridge University Press), 475-511.

Broersma, M. (2009). Triggered code switching between cognate languages. Biling. (Camb. Engl.) 12, 447-462.

Broersma, M., and De Bot, K. (2006). Triggered code switching: a corpusbased evaluation of the original triggering hypothesis and a new alternative. Biling. (Camb. Engl.) 9, 1-13.

Broersma, M., Isurin, L., Bultena, S., and De Bot, K. (2009). "Triggered code switching: evidence from Dutch-English and Russian-English bilinguals," in Multidisciplinary Approaches to Code Switching, eds L. Isurin, D. Winford, and K. De Bot (Amsterdam: John Benjamins), 103-128. 
Calsamiglia, H., and Tuson, A. (1984). Use of languages and code switching in groups of youths in a Barri of Barcelona. Int. J. Soc. Lang. 47, 105-121.

Carlson, S. M., and Meltzoff, A. N. (2008). Bilingual experience and executive functioning in young children. Dev. Sci. 11, 282-298.

Clyne, M. (1967). Transference and Trigerring: Observations on the Language Assimilation of Post-War German-Speaking Migrants in Australia. The Hague: Martinus Nijhoff.

Clyne, M. (1972). Perspectives on Language Contact. Melbourne: The Hawthorn Press.

Clyne, M. (2003). Dynamics of Language Contact. Cambridge: Cambridge University Press.

Colomé, A. (2001). Lexical activation in bilinguals' speech production: language-specific or languageindependent? J. Mem. Lang. 45, 721-736.

Comeau, L., Genesee, F., and Lapaquette, L. (2003). The modeling hypothesis and child bilingual codemixing. Int. J. Biling. 7, 113-126.

Cooper, R. P., and Shallice, T. (2006). Hierarchical schemas and goals in the control of sequential behavior. Psychol. Rev. 113, 887-916.

De Bot, K. (2004). The multilingual lexicon: modeling selection and control. Int. J. Multiling. 1, 17-32.

Dong, Y., Gui, S. S., and MacWhinney, B. (2005). Shared and separate meanings in the bilingual mental lexicon. Biling. (Camb. Engl.) 8, 221-238.

Eriksen, B. A., and Eriksen, C. W. (1974). Effects of noise letters upon the identification of a target letter in a nonsearch task. Percept. Psychophys. 16, 143-149.

Festman, J., Rodriguez-Fornells, A., and Münte, T. F. (2010). Individual differences in control of language interference in late bilinguals are mainly related to general executive abilities. Behav. Brain Funct. 6,5 .

Francis, W. S. (2005). "Bilingual semantic and conceptual representation," in Handbook of Bilingualism: Psycholinguistic Approaches, eds J. F. Kroll and A. M. B. De Groot (New York: Oxford University Press), 251-267.

Genesee, F., Paradis, J., and Crago, M. B. (2004). Dual Language Development and Disorders. A Handbook on Bilingualism and Second Language Learning. Baltimore: Paul $\mathrm{H}$. Brookes Publishing.

Giesbers, H. (1989). Code-Switching Tussen Dialect en Standaardtaal. Amsterdam: P.J. Meertens-Instituut.
Gollan, T. H., and Ferreira, V. S. (2009). Should I stay or should I switch? A cost-benefit analysis of voluntary language switching in young and aging bilinguals. $J$. Exp. Psychol. Learn. Mem. Cogn. 35, 640-665.

Gollan, T. H., Sandoval, T., and Salmon, D. P. (2011). Cross-language intrusion errors in aging bilinguals reveal the link between executive control and language selection. Psychol. Sci. 22, 1155-1164.

Green, D. (1998). Schemas, tags and inhibition. Biling. (Camb. Engl.) 1, 100-104.

Green, D. W. (1986). Control, activation, and resource: a framework and a model for the control of speech in bilinguals. Brain Lang. 27, 210-223.

Green, D. W. (2011). Language control in different contexts: the behavioral ecology of bilingual speakers. Front. Psychol. 2:103. doi:10.3389/fpsyg.2011.00103

Grosjean, F. (1982). Life with Two Languages: An Introduction to Bilingualism. Cambridge, MA: Harvard University Press.

Grosjean, F. (1998). Studying bilinguals: methodological and conceptual issues. Biling. (Camb. Engl.) 1, 131-149.

Gullberg, M., Indefrey, P., and Muysken, P. (2009). "Research techniques for the study of code-switching," in The Cambridge Handbook of Linguistic Code-Switching, eds B. E. Bullock and A. J. Toribio (Cambridge: Cambridge University Press), 21-39.

Gumperz, J. J. (1982). Discourse Strategies. Cambridge: Cambridge University Press.

Hatch, E. (1976). "Studies in language switching and mixing," in Language and Man: Anthropological Issues, eds W. C. McCormack and S. A. Wurm (The Hague: Mouton), 201-214.

Hilchey, M. D., and Klein, R. M. (2011). Are there bilingual advantages on nonlinguistic interference tasks? Implications for the plasticity of executive control processes. Psychon. Bull. Rev. 18, 625-658.

Hu, L., and Bentler, P. M. (1999). Cutoff criteria for the fit indexes in covariance structure analysis: conventional criteria versus new alternatives. Struct. Equ. Modeling 6, 1-55.

Jöreskog, K., and Sörbom, D. (2001). Lisrel 8: Structural Equation Modeling with the SIMPLIS Command Language. Hillsdale, NJ: Lawence Erlbaum.

Kaiser, H. F. (1974). An index of factorial simplicity. Psychometrika 39, 31-36.

Kootstra, G. J., Van Hell, J. G., and Dijkstra, T. (2009). "Two speakers, one dialogue: an interactive alignment perspective on code-switching in bilingual speakers," in Multidisciplinary Approaches to Code Switching, eds L. Isurin, D. Winford, and K. De Bot (Amsterdam: John Benjamins), 129-160.

Kootstra, G. J., Van Hell, J. G., and Dijkstra, T. (2010). Syntactic alignment and shared word order in code-switched sentence production: evidence from bilingual monologue and dialogue. J. Mem. Lang. 63 210-231.

Krämer, U., Cunillera, T., Càmara, E., Marco-Pallarés, E., Cucurell, D. Nager, W., Bauer, P., Schüle-Freyer, R., Schöls, L., Rodriguez-Fornells, A., and Münte, T. F. (2007). The impact of COMT and DRD4 genotypes on neurophysiological markers of performance monitoring. J. Neurosci. 27, 14190-14198.

Kroll, J. F., Bobb, S. C., and Wodniecka, Z. (2006). Language selectivity is the exception, not the rule: arguments against a fixed locus of language selection in bilingual speech. Biling. (Camb. Engl.) 9, 119-135.

Kroll, J. F., and Tokowicz, N. (2001). "The development of conceptual representation for words in a second language," in One Mind, Two Languages: Bilingual Language Processing, ed. J. L. Nicol (Malden, MA: Blackwell), 49-71.

La Heij, W. (2005). "Selection processes in monolingual and bilingual lexical access," in Handbook of Bilingualism: Psycholinguistic Approaches, eds J. F. Kroll and A. M. B. de Groot (New York: Oxford University Press), 289-307.

Li, P., and Farkas, I. (2002). "A selforganizing connectionist model of bilingual processing," in Bilingual Sentence Processing, eds R. Heredia and J. Altarriba (North-Holland: Elsevier Science Publishers), 59-85.

Linck, J. A., Kroll, J. F., and Sunderman, G. (2009). Losing access to the native language while immersed in a second language. evidence for the role of inhibition in secondlanguage learning. Psychol. Sci. 20, 1507-1515.

Lipski, J. (1978). "Code-switching and the problem of bilingual competence," in Aspects of Bilingualism, ed. M. Paradis (Columbia: Hornbeam Press), 250-264.

Logan, G. D. (1995). "On the ability to inhibit thought and action: a users guide to the stop signal paradigm," in Inhibitory Processes in Attention, Memory, and Language, eds D. Dagenbach and T. H.
Carr (San Diego: Academic Press), 189-239.

Lorenzo-Seva, U., and Ferrando, P. J. (2006). FACTOR: a computer program to fit the exploratory factor analysis model. Behav. Res. Methods Instrum. Comput. 38, 88-91.

Marco-Pallares, J., Camara, E., Münte, T. F., and Rodriguez-Fornells, A. (2008). Neural mechanisms underlying adaptive actions after slips. $J$. Cogn. Neurosci. 20, 1595-1610.

Marian, V. (2009). "Language interaction as a window into bilingual cognitive architecture," in Multidisciplinary Approaches to Code Switching, eds L. Isurin, D. Winford, and K. De Bot (Amsterdam: John Benjamins), 161-185.

Marshall, J. C., and Morton, J. (1978). "On the mechanics of EMMA," in The Child's Conception of Language, eds A. Sinclair, R. J. Jarvella, and W. J. M. Levelt (New York: SpringerVerlag), 225-239.

McLaughlin, B. (1984). SecondLanguage Acquisition in Childhood, Vol. 1, Preschool Children. Hillsdale, NJ: Lawrence Erlbaum.

McNamara, J., and Kushnir, S. (1971). Linguistic independence of bilinguals: the input switch. J. Verbal Learn. Verbal Behav. 10, 480-487.

Meuter, R. F., and Allport, A. (1999). Bilingual language switching in naming: asymmetrical costs of language selection. J. Mem. Lang. 40, 25-40.

Miccio, A. W., Scheffner-Hammer, C., and Rodriguez, B. (2009). "Codeswitching and language disorders in bilingual children," in Cambridge Handbook of Linguistic CodeSwitching, eds B. E. Bullock, A. Toribio, and J. Almeida (Cambridge: Cambridge University Press), 259-270.

Milroy, L., and Gordon, M. J. (2003). Sociolinguistics: Method and Interpretation. Malden, MA: Blackwell.

Möller, J., Jansma, B. M., RodriguezFornells, A., and Münte, T. F. (2007). What the brain does before the tongue slips. Cereb. Cortex 17, 1173-1178.

Moreno, E. M., Rodriguez-Fornells, A., and Laine, M. (2008). Eventrelated potentials (ERPs) in the study of bilingual language processing. J. Neurolinguistics 21, 477-508.

Morton, J. B., and Harper, S. N. (2007). What did Simon say? Revisiting the bilingual advantage. Dev. Sci. 10, 719-726.

Muthén, B., and Kaplan, D. (1985). A comparison of some methodologies for the factor analysis of non-normal Likert variables. Br. J. Math. Stat. Psychol. 38, 171-189. 
Muthén, B., and Kaplan, D. (1992). A comparison of some methodologies for the factor analysis of non-normal Likert variables: a note on the size of the model. Br. J. Math. Stat. Psychol. $45,19-30$.

Norman, D. A., and Shallice, T. (1986). "Attention to action: willed and automatic control of behavior," in Consciousness and Self-Regulation, Vol. 4, eds R. J. Davison, G. E. Schwartz, and D. Shapiro (New York: Plenum), 1-18.

Nozari, N., Dell, G. S., and Schwartz, M. F. (2011). Is comprehension necessary for error detection? A conflictbased account of monitoring in speech production. Cogn. Psychol. $63,1-33$.

Odlin, T. (1989). Language Transfer: Crosslinguistic Influence in Language Learning. Cambridge: Cambridge University Press.

Owens, J. (2005). Bare forms and lexical insertions in code switching: a processing-based account. Biling. (Camb. Engl.) 8, 23-38.

Petitto, K. M., Levy, B. G., Gauna, K., Tetreault, K., and Ferraro, V. (2001). Bilingual signed and spoken language acquisition from birth: implications for the mechanisms underlying early bilingual language acquisition. J. Child Lang. 28, 453-496.

Poplack, S. (1980). Sometimes I'll start a sentence in Spanish y termino en Español: toward a typology of code-switching. Linguistics 18, 581-618.

Poplack, S. (1985). "Contrasting patterns of code-switching in two communities," in Methods V: Papers from the $V$ International Conference on Methods in Dialectology, ed. H. Warkentyne (Victoria,
BC: University of Victoria Press), 363-386.

Poulisse, N., and Bongaerts, T. (1994). First language use in second language production. Appl. Linguist. 15, 36-57.

Prior, A., and Gollan, T. H. (2011). Good language-switchers are good task-switchers: evidence from Spanish-English and Mandarin-English bilinguals. J. Int. Neuropsychol. Soc. 17, 1-10.

Prior, A., and MacWhinney, B. (2010). A bilingual advantage in task switching. Biling. (Camb. Engl.) 13, 253-262.

Ritchie, W. C., and Bhatia, T. (2006). "Social and psychological factors in language mixing," in The Handbook of Bilingualism, eds T. K. Bhatia and W. C. Ritchie (Oxford: Blackwell Publishing), 336-352.

Rodriguez-Fornells, A., de Diego Balaguer, R., and Münte, T. F. (2006). Executive functions in bilingual language processing. Lang. Learn. 56, 133-190.

Rodriguez-Fornells, A., Rotte, M., Noesselt, T., and Heinze, H. J, Münte, T. F. (2002a). Brain potential and functional MRI evidence for how to handle two languages with one brain. Nature 415, 1026-1029.

Rodríguez-Fornells, A., Lorenzo-Seva, U., and Andrés-Pueyo, A. (2002b). Are high-impulsive and high risk-taking people more motor disinhibited in the presence of incentive? Pers. Individ. Dif. 32, 661-683.

Rodriguez-Fornells, A., Van der Lugt, A., Rotte, M., Britti, B., Heinze, H. J., and Münte, T. F. (2005). Second language interferes with word production in fluent bilinguals: brain potential and functional imaging evidence. $J$. Cogn. Neurosci. 17, 422-433.

Shallice, T. (2004). "The fractionation of supervisory control," in The Cognitive Neurosciences, 3rd Edn, ed. M. S. Gazzaniga (Cambridge, MA: MIT Press), 943-956.

Soveri, A., Rodriguez-Fornells, A., and Laine, M. (2011). Is there a relationship between bilingual language switching and executive functions? Introducing a within-group analysis approach. Front. Psychol. 2:183. doi: 10.3389/fpsyg.2011.00183

Sridhar, S., and Sridhar, K. (1980). The syntax and psycholinguistics of bilingual code mixing. Can. J. Psychol. 34, 407-416.

Stroop, J. R. (1935). Studies of interference in serial verbal reactions. J. Exp. Psychol. 18, 643-662.

Ten Berge, J. M. F., and Kiers, H. A L. (1991). A numerical approach to the approximate and the exact minimum rank of a covariance matrix. Psychometrika 56, 309-315.

Timm, L. A. (1975). Spanish-English code-switching: El Porqué and hownot-to. Roman. Philol. 28. 473-482.

Van Hell, J. G., and De Groot, A. M. B. (1998). Conceptual representation in bilingual memory: effects of concreteness and cognate status in word association. Biling. (Camb. Engl.) 3 , 193-211.

Weber-Fox, C., and Neville, H. J. (1996). Maturational constraints on functional specializations for language processing: ERP and behavioral evidence in bilingual speakers. J. Cogn. Neurosci. 8, 231-256.

Weinreich, U. (1953). Languages in Contact. The Hague: Mouton.

Woolard, K. A. (1988). "Code switching and comedy in catalonia," in Code
Switching. Anthropological and Sociolinguistic Perspectives, ed. M. Heller (New York: Mouton de Gruyter), 53-66.

Ye, Z., and Zhou, X. (2009). Executive control in language processing. Neurosci. Biobehav. Rev. 33, 1168-1177.

Yeung, N. (2010). Bottom-up influences on voluntary task switching: the elusive homunculus escapes. $J$. Exp. Psychol. Learn. Mem. Cogn. 36, 348-362.

Zentella, A. (1997). Growing Up Bilingual. Malden, MA: Blackwell.

Conflict of Interest Statement: The authors declare that the research was conducted in the absence of any commercial or financial relationships that could be construed as a potential conflict of interest.

Received: 30 April 2011; accepted: 09 December 2011; published online: 10 January 2012.

Citation: Rodriguez-Fornells A, Krämer UM, Lorenzo-Seva U, Festman J and Münte TF (2012) Self-assessment of individual differences in language switching. Front. Psychology 2:388. doi: 10.3389/fpsyg.2011.00388

This article was submitted to Frontiers in Cognition, a specialty of Frontiers in Psychology.

Copyright (c) 2012 Rodriguez-Fornells, Krämer, Lorenzo-Seva, Festman and Münte. This is an open-access article distributed under the terms of the Creative Commons Attribution Non Commercial License, which permits noncommercial use, distribution, and reproduction in other forums, provided the original authors and source are credited. 


\section{APPENDIX \\ BSWO SPANISH VERSION}

Trate de contestar en que medida las siguientes preguntas representan o se ajustan a su forma de hablar y expresarte en los idiomas que conoce (p. ej., Catalán-Español), en términos generales. Muchas de estas preguntas hacen referencia a si usted cambia o mezcla frecuentemente el catalán y el castellano en sus conversaciones. Cambiar o mezclar lenguajes es una característica muy particular de algunos entornos bilingües, como es el caso en Cataluña. El siguiente cuestionario pretende investigar sobre dichos hábitos de cambio y mezcla de lenguas. Si tiene dudas sobre algunas respuestas, intente comparar su forma de hablar y expresarte con el de la mayoría, o de las personas que conoce bien.

1. Me faltan o no recuerdo algunas palabras en CATALÁN cuando estoy hablando en dicho idioma.

$\square$ nunca $\square$ muy raramente $\square$ ocasionalmente $\square$ frecuentemente $\square$ siempre

2. Me faltan o no recuerdo algunas palabras en ESPAÑOL cuando estoy hablando en dicho idioma.

3. Tiendo a mezclar idiomas durante una conversación (por ejemplo, cambio de español a catalán o a la inversa).

4. Cuando no me sale una palabra en CATALÁN, tiendo a producirla inmediatamente en ESPAÑOL.

5. Cuando no me sale una palabra en ESPAÑOL, tiendo a producirla inmediatamente en CATALÁN.

6. Cuando cambio de idioma (p. ej., de catalán a español) o los mezclo, no me doy cuenta de que lo estoy haciendo y suelen ser los otros los que me lo dicen.

7. Cuando mezclo un idioma lo hago conscientemente.

8. Me resulta difícil controlar los cambios de idioma que introduzco (p. ej., de catalán a castellano) a lo largo de una conversación.

9. Sin quererlo, a veces me sale primero la palabra en ESPAÑOL cuando estoy hablando en CATALÁN.

10. Sin quererlo, a veces me sale primero la palabra en CATALÁN cuando estoy hablando en español.

11. Hay situaciones en las cuales siempre mezclo dos idiomas.

12. Hay asuntos o temas sobre los cuales suelo hablar mezclando ambos idiomas.

POR FAVOR, COMPRUEBE SI HA RESPONDIDO A TODAS LAS PREGUNTAS

\section{BSWO ENGLISH TRANSLATION}

Please, try to answer to what degree the following questions are representative of the manner you use to talk or speak in the language you know (e.g., Catalan-Spanish). Many of these questions ask you to report your tendency to switch or mix languages during a conversation. Switching and mixing languages is a characteristic of some bilingual contexts or environments, as for example in Catalonia. The present questionnaire aims to identify the language switching patterns that exist in these languages. If you have doubts about how to rate yourself in the following questions, please try to compare your manner of speaking and talking with that of most people, or those who you know very well.

1. I do not remember or I cannot recall some Catalan words when I am speaking in this language.

$\square$ never $\square$ very infrequently $\square$ occasionally $\square$ frequently $\square$ always

2. I do not remember or I cannot recall some Spanish words when I am speaking in this language.

3. I tend to switch languages during a conversation (for example, I switch from Spanish to Catalan or vice versa).

4. When I cannot recall a word in Catalan, I tend to immediately produce it in Spanish.

5. When I cannot recall a word in Spanish, I tend to immediately produce it in Catalan.

6. I do not realize when I switch the language during a conversation (e.g., from Catalan to Spanish) or when I mix the two languages; I often realize it only if I am informed of the switch by another person.

7. When I switch languages, I do it consciously.

8. It is difficult for me to control the language switches I introduce during a conversation (e.g., from Catalan to Spanish).

9. Without intending to, I sometimes produce the Spanish word faster when I am speaking in Catalan.

10. Without intending to, I sometimes produce the Catalan word faster when I am speaking in Spanish.

11. There are situations in which I always switch between the two languages.

12. There are certain topics or issues for which I normally switch between the two languages.

PLEASE, CHECK IF YOU HAVE ANSWERED ALL THE QUESTIONS 